\title{
IMPACT CRACK INITIATION AND PROPAGATION ENERGY OF Prolonged EXPloited HeAt Resistant STEEL
}

\author{
Damir Hodzic \& Ismar Hajro
}
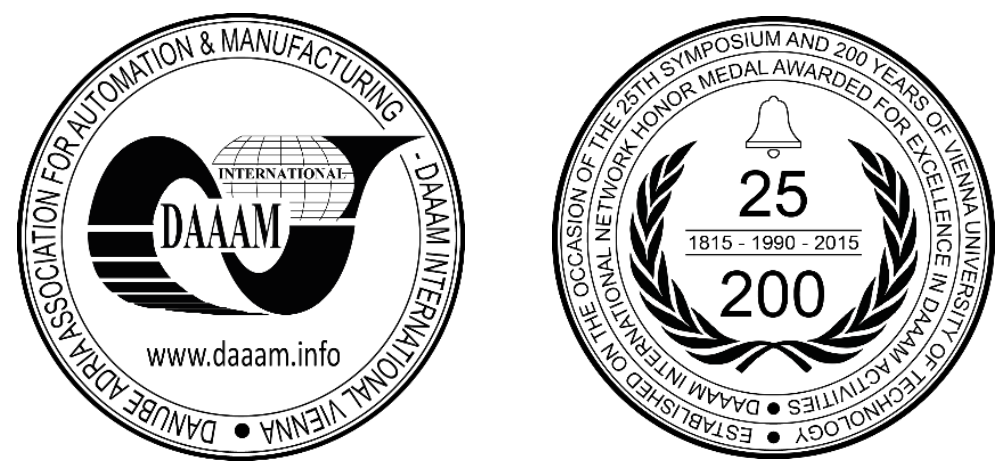

This Publication has to be referred as: Hodzic, D[amir] \& Hajro, I[smar] (2016). Impact Crack Initiation and Propagation Energy of Prolonged Exploited Heat Resistant Steel, Proceedings of the 27th DAAAM International Symposium, pp.0308-0311, B. Katalinic (Ed.), Published by DAAAM International, ISBN 978-3-902734-08-2, ISSN 1726-9679, Vienna, Austria

DOI: $10.2507 / 27$ th.daaam.proceedings.045

\begin{abstract}
In this paper heat resistant steel 14MoV6-3 in conditions as a virgin and exploited material is investigated. This steel was used for the main steamline of thermal power plant for a prolonged life time period under service conditions. As a consequence of microstructure evolution through long period of exploitation at elevated temperature there was a significant decrease of mechanical properties. In order to investigate decrease of impact properties of steel 14MoV6-3, following temperatures were selected for impact testing: $20^{\circ} \mathrm{C}, 150{ }^{\circ} \mathrm{C}, 400{ }^{\circ} \mathrm{C}$ and $540{ }^{\circ} \mathrm{C}$ (service temperature). This was done by testing and comparison of impact crack initiation and propagation energy of virgin and serviced material 14MoV6-3 after 194.207 hours of exploitation. Irrespective to the fact that impact tests cannot be used for assessment of the further steamline safe service time, it is indispensable for assessing the materials deformability and its capability to carry the load in its further service process.
\end{abstract}

Keywords: Steel 14MoV6-3; Impact testing; Crack initiation and propagation energy; Lifetime assessment.

\section{Introduction}

Nevertheless to the very long history of low-alloyed steel 14MoV6-3, this material is still built in the numerous power plants, particularly in the boilers and its belonging high-temperature components. According to the German Codes VGB-R 509L and TRD 508 the start or extended material inspection is required after about 70.000 hours for steel 14MoV6-3 and about 100.000 hours of exploitation for the other heat resistant steels [1]. Power plants, which were originally intended to provide the base load, are frequently shut down and powered up. Variations in the steam temperature accompanying the power changes induce thermo-mechanical stresses in components, which lead to material degradation and consequently can cause failure [2]. The effort to extend designed lifetime of industrial plants operating for a long time at elevated temperatures requires the knowledge of residual lifetime of the critical components. Residual lifetime assessment is unthinkable without the knowledge of mechanical properties of materials prior to operation and mechanical properties after actual time of operation (actual mechanical properties), because the material properties can be reduced throughout the service life [3]. Decrease of mechanical properties of exploited material is caused by changes in the steel microstructure due to long-lasting service operation. Reduction of impact properties caused by long-term exploitation of the steel at elevated temperature depends to a large extent on the initial 
steel microstructure. Some published investigations reported that decrease of impact toughness caused by long-lasting operation is the least in the case of tempered bainite structure [4]. In addition to previous, metallographic examinations of various steel grades after long-term service at elevated temperature revealed that transformations of carbides and morphological changes of phases have the most significant effect on service properties degradation [5].

\section{Chemical composition and microstructure}

In order to investigate decrease of impact properties of material, low-alloyed steel 14MoV6-3 exposed to 194.207 hours of exploitation, has been compared with same, but virgin material. Investigated material is taken from the Unit 5 main steamline $(\varnothing 245 \times 28 \mathrm{~mm})$ that operated at temperature $540{ }^{\circ} \mathrm{C}$ and pressure $13,5 \mathrm{MPa}$ in thermal power plant Kakanj, Bosnia and Herzegovina. Chemical composition of investigated material 14MoV6-3 (virgin and exploited) was accomplished in order to confirm that all delivered specimens of steamline are made from the same material, so the results of predicted investigation on virgin and exploited material could be comparable. Method for determination of chemical composition was spectral analysis. Chemical composition of material 14MoV6-3 according to normative DIN $17175 / 79$ is presented in Table 1.

\begin{tabular}{|c|c|c|c|c|c|c|c|c|}
\hline Grade & C, \% & Si, \% & Mn, \% & P, \% & S, \% & Cr, \% & Mo, \% & V, \% \\
\hline 14MoV6-3 & $0,10-0,18$ & $0,10-0,35$ & $0,40-0,70$ & Max.0,035 & Max.0,035 & $0,30-0,60$ & $0,50-0,70$ & $0,22-0,32$ \\
\hline
\end{tabular}

Table 1. Chemical composition of steel 14MoV6-3 according to DIN 17175

From the results of chemical composition analysis it was obvious that investigated steamline specimens (virgin and exploited) are made of the same material 14MoV6-3. Slightly less content of Molybdenum, comparing with chemical composition according to DIN 17175, is probably error of measuring without influence on further investigation, because content of Molybdenum is almost the same for virgin and exploited steamline material. Chemical composition of investigated virgin and exploited material 14MoV6-3 is presented in Table 2 and Table 3, respectively.

\begin{tabular}{|c|c|c|c|c|c|c|c|c|}
\hline Grade & $\mathbf{C , ~ \%}$ & $\mathbf{S i}, \boldsymbol{\%}$ & Mn, \% & $\mathbf{P , ~ \%}$ & $\mathbf{S , ~ \%}$ & $\mathbf{C r}, \boldsymbol{\%}$ & Mo, \% & V, \% \\
\hline 14MoV6-3 & 0,149 & 0,30 & 0,57 & 0,013 & 0,015 & 0,59 & 0,475 & 0,28 \\
\hline
\end{tabular}

Table 2. Chemical composition of virgin steel 14MoV6-3

\begin{tabular}{|c|c|c|c|c|c|c|c|c|}
\hline Grade & $\mathbf{C ,} \boldsymbol{\%}$ & $\mathbf{S i}, \boldsymbol{\%}$ & $\mathbf{M n}, \boldsymbol{\%}$ & $\mathbf{P ,} \%$ & $\mathbf{S}, \boldsymbol{\%}$ & $\mathbf{C r}, \boldsymbol{\%}$ & $\mathbf{M o}, \boldsymbol{\%}$ & $\mathbf{V}, \boldsymbol{\%}$ \\
\hline 14MoV6-3 & 0,139 & 0,32 & 0,56 & 0,013 & 0,013 & 0,50 & 0,47 & 0,28 \\
\hline
\end{tabular}

Table 3. Chemical composition of exploited steel 14MoV6-3

In order to investigate microstructure of exploited steamline material, metallographic testing was accomplished. This was done in laboratory at IWS Institute TU Graz (Institute for materials and welding at Technical University Graz), Austria, by testing and comparison of microstructure of virgin material and exploited material 14MoV6-3 after 194.207 hours of exploitation. One specimen per material condition (virgin and exploited) was used and metallographic testing of material microstructure by optical microscope was done with different magnifications of $200 \times, 500 \times$ and 1000x. Microstructure of investigated material 14MoV6-3 at transversal cross section of steamline pipe with magnification $200 \times$ is shown in Fig. 1.
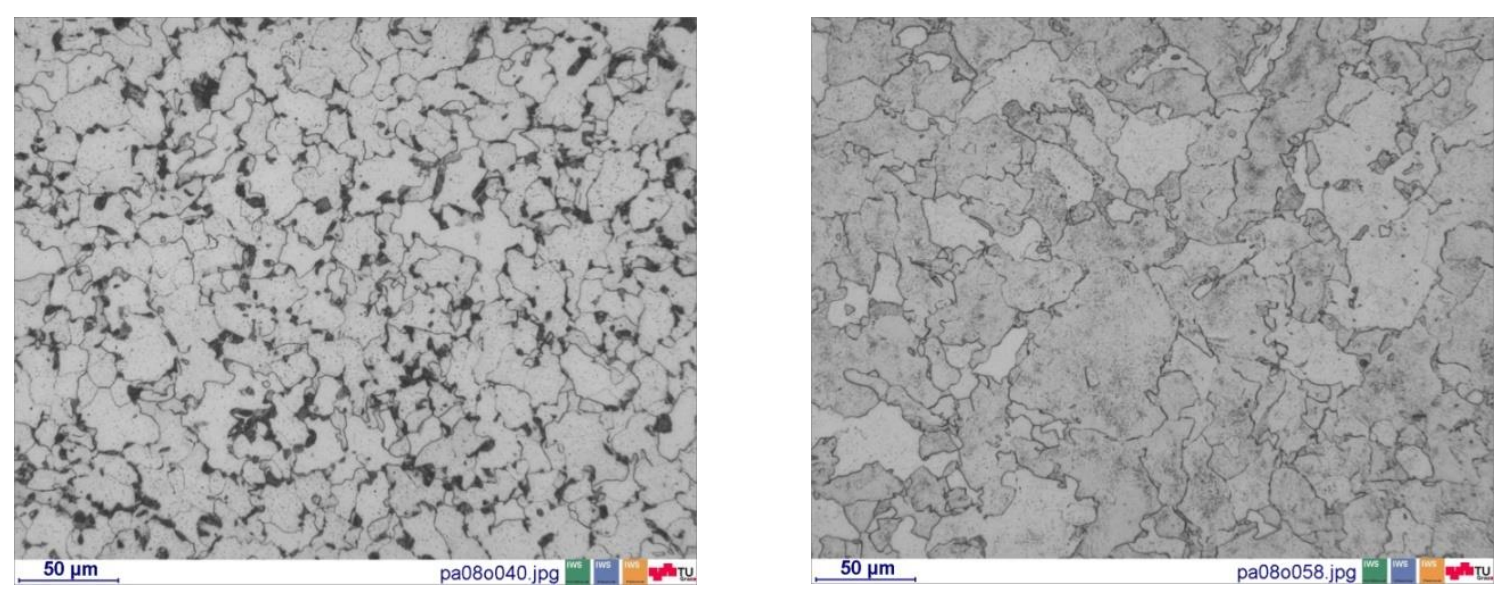

Fig. 1. Microstructure of virgin and exploited steel 14MoV6-3 [6] 
According to previous investigations of this material with similar service conditions, that are published in scientific journals, the initial microstructure of the 14MoV6-3 low-alloyed steel features the mixture of bainite with ferrite, sometimes with a small amount of pearlite. Occurrences of the significant amount of the $\mathrm{M}_{3} \mathrm{C}$ carbides and numerous, very fine $\mathrm{MC}$ type ones, are identified in such material. The final structure image after prolonged exploitation is ferrite with rather homogeneously distributed precipitations inside grains and chains of the significant amount of precipitations on their boundaries, [5]. Results of microstructure investigation that are presented in this paper mainly can confirm previous facts, but in addition to mentioned microstructure evolution, there is also a significant growth of ferrite grain size after long-term operation at elevated temperature.

\section{Impact testing of crack initiation and propagation energy}

In general, notch toughness is measured in terms of the absorbed impact energy needed to cause fracturing of the specimen. The change in potential energy of the impacting head (from before impact to after fracture) is determined with a calibrated dial that measures the total energy absorbed in breaking the specimen. Other quantitative parameters, such as fracture appearance and degree of ductility/deformation, are also often measured in addition to the fracture energy. Impact tests may also be instrumented to obtain load data as a function of time during the fracture event. The Charpy V-notch test continues to be the most utilized and accepted impact test in use in the industry, [7]. In order to investigate decrease of impact properties of exploited steamline material 14MoV6-3, following temperatures were selected for impact testing: $20{ }^{\circ} \mathrm{C}, 150{ }^{\circ} \mathrm{C}, 400{ }^{\circ} \mathrm{C}$ and $540{ }^{\circ} \mathrm{C}$ (service temperature). This was done by testing and comparison of crack initiation and propagation energy values of virgin material and exploited material 14MoV6-3 after 194.207 hours of exploitation. For every testing temperature 3 Charpy V-notch specimens were used. Results of average ( 3 specimens) impact crack initiation energy values per testing temperature for virgin and exploited material 14MoV6-3 are presented in Fig. 2.

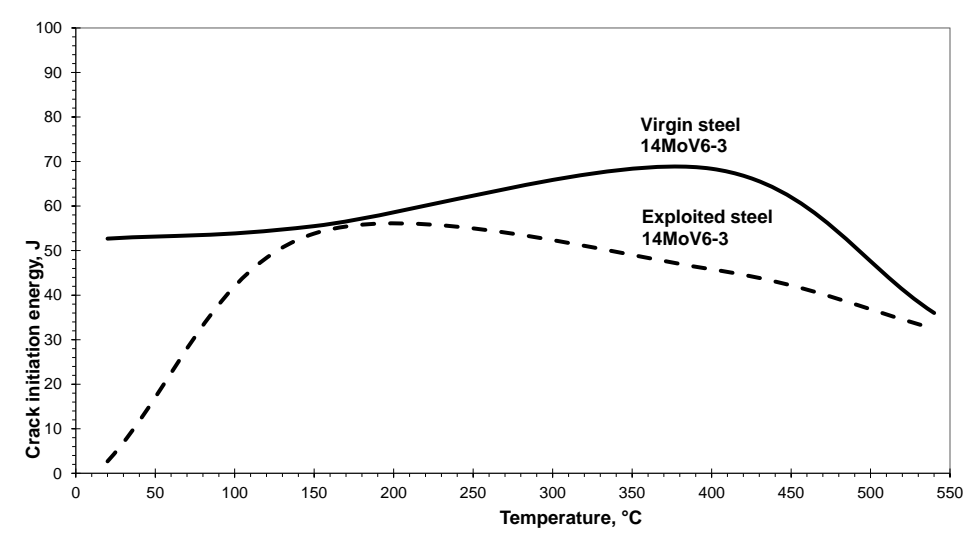

Fig. 2. Impact crack initiation energy

Results of average ( 3 specimens) impact crack propagation energy values per testing temperature for virgin and exploited material 14MoV6-3 are presented in Fig. 3.

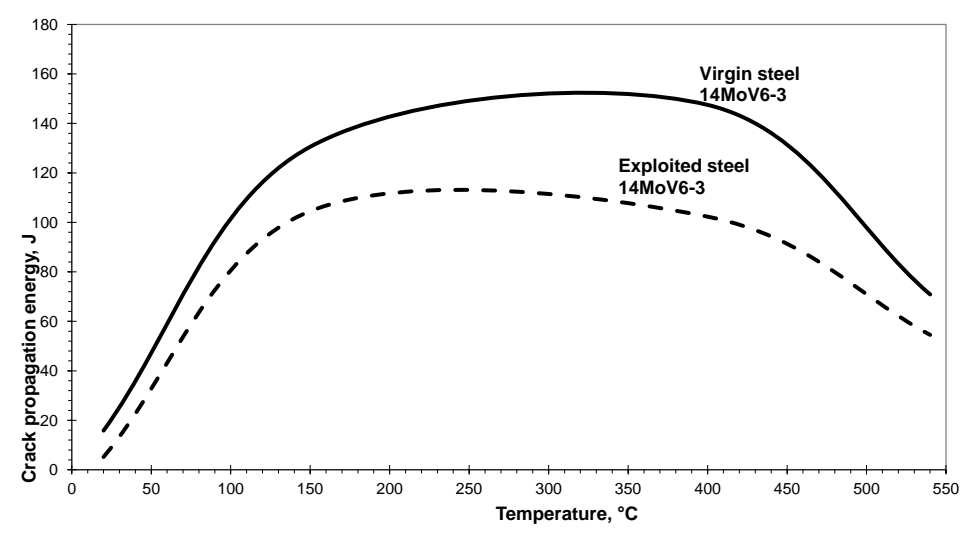

Fig. 3. Impact crack propagation energy

From the results of impact testing it is notable that the impact crack initiation and propagation energy increases slightly up to $400{ }^{\circ} \mathrm{C}$ for virgin material $14 \mathrm{MoV} 6-3$ and up to $150{ }^{\circ} \mathrm{C}$ for exploited material $14 \mathrm{MoV} 6-3$. It is reduces significantly, but not drastically above $400{ }^{\circ} \mathrm{C}$ for virgin material and above $150{ }^{\circ} \mathrm{C}$ for exploited material, so that its 
values are still more than sufficient at steamline service temperature $540{ }^{\circ} \mathrm{C}$. The most important result of exploited steamline material impact testing is extremely low value of impact crack initiation energy at room temperature $20^{\circ} \mathrm{C}$, which is significantly beneath the allowed value. Impact properties of steamline material 14MoV6-3 depends mostly on development of the precipitation processes and also on development of the microstructure changes and structure discontinuities, as well as grain growth, originated during the long period of exploitation at elevated temperature.

\section{Lifetime assessment}

Components of power plant boiler are exposed to elevated temperatures, aggressive environment, creep, fatigue, and other damage mechanisms that can cause degradation, deformation or cracking of components. Boiler components and belonging steamlines of thermal power plants have exceeded most often significantly their design service time being most often 100.000 hours long. They require forecasting their further safe service for the conditions in exploitation. Evaluation of microstructural evolution in exposed to service materials is a key tool for a correct evaluation of material status and allowable service extension. The knowledge of the structure and degree of damage could be essential for the assessment of residual service life and damage analysis respectively. It should however be pointed out that the above mentioned knowledge alone does not allow a prediction of the residual service life. A reliable life assessment should be made not only by means of microstructural inspection but it is preferable that together with other inspections the same is included. A large number of failures in engineering components occur due to preexisting defects, nonmetallic inclusions or other imperfections (casting, welding defects, etc.) [8]. However, it is of engineering interest to know how and why particular component has failed.

\section{Conclusion}

Main problem with impact testing is that it cannot be used for the final assessment of the further steamline safe service time and it is not quite useful for the residual life assessment and for determining of the exhaustion extent. Very low impact toughness values of investigated exploited steel 14MoV6-3 could cause crack initiation and propagation by extremely low impact load level in service at room temperature. Results of this investigation show that impact testing should be obviously included together with the other diagnostic methods as a very important indicator. However, it is indispensable for assessing the material's deformability and its capability to carry the load connected with the pressure tests, as well as in limiting the number of banking and setting to work the steamline in its further service process. In the future, not only impact toughness but also the other parameters of fracture mechanics such as fracture toughness could be very interesting for investigation of prolonged exploited heat resistant steels used in power plants.

\section{Acknowledgement}

This investigation was partly supported by IWS Institute at Technical University Graz and OEAD Austrian Agency for International Cooperation in Education and Research.

\section{References}

[1] ECCC Recommendations - Volume 9, Part II: High Temperature Component Analysis Overview of Assessment \& Design Procedures, ECCC European Creep Collaborative Committee, 2005

[2] Linn, S., Scholz A. (2013). Creep-fatigue Lifetime Assessment with Phenomological and Constitutive Material Laws. Procedia Engineering (6th International Conference on Creep, Fatigue and Creep-Fatigue Interaction CF-6), Vol. 55, 2013, pp. 607-611, ISSN1877-7058, DOI 10.106/j.proeng.2013.03.302

[3] Matocha K. (2014). The Use of Small Punch Test for Determination of Fracture Behaviour of Ferritic Steels. Procedia Engineering (1st International Conference on Structural Integrity ICONS-2014), Vol. 86, 2014, pp. 885891, ISSN1877-7058, DOI 10.106/j.proeng.2014.11.110

[4] Golanski G., Stachura S., Gajda-Kucharska B., Kupczyk J. (2007). Optimisation of Regenerative Heat Treatment Parameters of G21CrMoV4-6 Cast Steel. Archives of Materials Science and Engineering, Vol. 28, No. 6, (June 2007) page numbers (341-344), ISSN 1897-2764

[5] Dobrzanski J., Zielinski A., Krtzon H. (2007). Mechanical Properties and Structure of the Cr-Mo-V Low-alloyed Steel after Long-term Service in Creep Condition. Journal of Achievements in Materials and Manufacturing Engineering, Vol. 23, No. 1, (July 2007) page numbers (39-42), ISSN 1734-8412

[6] Hodzic D., Hajro I. (2012). Microstructure Degradation after Prolonged Exploitation of Heat Resistant Steel 14MoV6-3. Proceedings of 16th International Research/Expert Conference "Trends in the Development of Machinery and Associated Technology", 10-12 September 2012, Dubai UAE, ISSN 1840-4944, Ekinović S., Yalcin S., Calvet J.V. (Ed.), pp. 155-158, Faculty of Mechanical Engineering in Zenica, Zenica

[7] ASM Handbook Vol. 8 - Mechanical testing and evaluation, Impact toughness testing, ASM International, 2000

[8] Brnic J., Brcic M. (2015). Comparison of Mechanical Properties and Resistance to Creep of 20MnCr5 Steel and X10CrAlSi25. Procedia Engineering (25th DAAAM International Symposium on Intelligent Manufacturing and Automation, 2014), Vol. 100, 2015, pp. 84-89, ISSN1877-7058, DOI 10.106/j.proeng.2015.01.345 